\title{
Relationship between autoantibodies against glutamic acid decarboxylase, thyroglobulin/thyroid microsome and DNA topoisomerase II in the clinical manifestation of patients with type 1 diabetes mellitus in Taiwan
}

\author{
Ming-Yuh Shiau ${ }^{1}$, Shih-Tzer Tsai ${ }^{2}$, Jaulang Hwang ${ }^{3}$, Chun-Ying $\mathrm{Wu}^{4}$ and Yih-Hsin Chang ${ }^{5}$ \\ ${ }^{1}$ Hung Kuang Institute of Technology, Taichung, Republic of China, ${ }^{2}$ Department of Medicine and Clinical Research Center, Veterans General Hospital, \\ Taipei, Republic of China, ${ }^{3}$ Institute of Molecular Biology, Academia Sinica, Nankang, Republic of China, ${ }^{4}$ China Medical College and ${ }^{5}$ School of \\ Medical Technology, Chung Shan Medical and Dental College, Taichung, Taiwan, Republic of China \\ (Correspondence should be addressed to Yih-Hsin Chang; Email: cyh@mercury.csmc.edu.tw)
}

\begin{abstract}
Objective: In a preliminary cross-sectional study, we discovered that DNA topoisomerase II autoantibodies (anti-TopII) were detected in $49.2 \%$ of 195 Chinese type 1 diabetes mellitus (type $1 \mathrm{DM}$ ) patients with a mean age of 14.5 years and a mean duration of disease of 4.6 years. In order to demonstrate the relationship between anti-TopII and other immunological characteristics in Chinese type $1 \mathrm{DM}$ patients, and to evaluate its putative prediction efficacy in Chinese patients, we simultaneously examined the frequency of anti-glutamic acid decarboxylase autoantibodies (anti-GAD), anti-TopII, antithyroglobulin/antimicrosomal autoantibodies (ATA/AMiA) and C-peptide concentrations in our patients in the present study.

Design and Methods: The frequency of anti-GAD and C-peptide levels, anti-TopII, and ATA/AMiA were examined in our patients by radioimmunoassay, enzyme-linked immunosorbant assay and hemagglutination respectively. Univariate comparisons were performed using Student's t-test for normal distributed data and Chi-square test for diclomatous data. Multivariate analysis was used for interpreting the independent risk factors which increased the incidence of anti-TopII.

Results and Conclusions: The positivities for anti-GAD, anti-TopII, ATA/AMiA and C-peptide were $45.8 \%, 50.2 \%, 13.4 \%$ and $11.4 \%$ respectively. Anti-GAD and anti-TopII frequencies in our patients were similar when we stratified the patients by age, age at onset and duration. These observations imply that anti-GAD and anti-TopII remain persistent in Chinese patients with long-term type $1 \mathrm{DM}$ duration. The most interesting finding is that anti-TopII frequency is more persistent than anti-GAD in our patients, especially when the diabetic duration is longer than 11 years. This indicates that antiTopII, rather than anti-GAD, might act as a better indicator for monitoring the pathogenesis of Chinese type $1 \mathrm{DM}$ patients especially in patients with a long-standing duration of disease. The late age of onset (>18 years) is a risk factor which increased the incidence of anti-TopII according to multivariate analysis. We further analyzed different manifestations between the youth- and adult-onset type $1 \mathrm{DM}$ and found that adult-onset type $1 \mathrm{DM}$ is characterized by better preservation of residual $\beta$-cell function and higher frequencies of autoantibodies.
\end{abstract}

European Journal of Endocrinology 142 577-585

\section{Introduction}

Type 1 diabetic mellitus (type $1 \mathrm{DM}$ ) is an autoimmune disorder in which T-cell-dependent $\beta$-cell destruction occurs in genetically susceptible hosts $(1-5)$. Patients with type $1 \mathrm{DM}$ are associated with several types of autoantibodies against a variety of cellular components such as islet-cell cytoplasmic antigens (ICA), glutamic acid decarboxylase (GAD), heat shock protein 65, carboxypeptidase $\mathrm{H}$, insulin, and the most recently identified tyrosine phosphatase-like molecules, IA-2 and
IA-2 $\beta$ (6-17). Among these autoantibodies, combined analysis of autoantibodies against GAD (anti-GAD) and IA-2 (anti-IA-2) has been proved to have a high and consistent diagnostic sensitivity and specificity for type 1 DM according to several recent studies $(18,19)$. AntiGAD and anti-IA-2 can be detected in about 70-90\% and up to $80 \%$ of newly diagnosed Caucasian type $1 \mathrm{DM}$ patients respectively $(14,20,21)$. Although the prevalence of anti-IA-2 in Chinese type 1 DM patients has not been reported yet, seropositivity of anti-GAD is relatively low in Chinese type $1 \mathrm{DM}$ patients compared 
with that of Caucasoid patients (22). In addition, the associations of human leucocyte antigen in Chinese type $1 \mathrm{DM}$ patients have been reported to be gender- and age-related and may be different from those in Caucasians $(23,24)$. All the above observations suggest the involvement of multiple autoantigens and genetic differences might result in different processes of the heterogenous autoimmune responses in Chinese type 1 DM pathogenesis. However, most of the research work referring to type $1 \mathrm{DM}$ has been focused on Caucasian subjects, and the correlation between various autoantibodies in Chinese type $1 \mathrm{DM}$ patients has never been established.

The topological state of DNA is an important determinant for DNA structure and function. Two fundamentally different types of DNA topoisomerases are found in nature: DNA type I topoisomerase breaks and rejoins only one of the two strands for each DNA strand-passing reaction, while DNA type II topoisomerase (TopII) breaks and rejoins both strands for each DNA strand-passing reaction (24-27). In a previous crosssectional study, we used purified overlapping TopII fragments as antigens to examine sera of 195 Chinese type $1 \mathrm{DM}$ patients (28). The results showed that TopII autoantibodies (anti-TopII) were detected in 49.2\% of our patients. We also discovered up to $55.6 \%$ homology between GAD and the central region of TopII and, therefore, inferred that anti-TopII might derive from the antigenic mimicry to GAD in our previous study. In order to demonstrate the relationship between antiTopII with other immunological characteristics in Chinese type $1 \mathrm{DM}$ patients and to evaluate its putative prediction efficacy in Chinese patients, we simultaneously examined the frequency of anti-GAD, anti-TopII, antithyroglobulin/ antimicrosomal autoantibodies (ATA/AMiA) and Cpeptide concentrations in our patients in the present study. The most striking finding in this study is that we found anti-TopII to be more constant and persistent than anti-GAD in our patients, especially in the subgroup of patients with long-standing duration of diabetes (more than 11 years); whereas generally there is no significant difference in the prevalence of antiTopII and anti-GAD in our patients when they are stratified by age and age at onset. This observation indicates that anti-TopII is probably a better indicator for the prediction of the disease or for monitoring the disease treatment in Chinese patients.

The incidence rate of Caucasian type $1 \mathrm{DM}$ is reported to be bimodal: one peak occurs close to puberty and another in the fifth decade. The pattern of incidence of type $1 \mathrm{DM}$ with two peaks may reflect age-related differences in the pathogenesis of the disease. There are few reports relating to the adult-onset Chinese type 1 DM because of its low incidence in Chinese people. We therefore divided our patients according to their age of onset to examine whether there is any difference in terms of immunological manifestation(s) between these two subgroups of Chinese type $1 \mathrm{DM}$. We discovered that
Chinese type 1 DM that begins in adulthood is characterized by preservation of residual $\beta$-cell function and higher anti-TopII frequency and further univariate and multivariate analysis confirms the prevalence of anti-TopII associated with late- or adult-onset Chinese type $1 \mathrm{DM}$.

Another subtype of type $1 \mathrm{DM}$ is the slowly progressive or latent autoimmune diabetes in adults (LADA) (29). Characteristics of these patients include a significantly higher age of onset compared with acute onset type 1 DM, with a peak at around 30-50 years. Patients with LADA share the classical type 1 DM clinical manifestations including being non-obese, insulin-requiring, with a history of ketoacidosis and low C-peptide levels $(30,31)$. It is also intriguing for us to analyze the correlation of anti-TopII with the eventual requirement of insulin treatment in Chinese type 2 DM patients. However, we cannot provide any clue so far as to the predictive power of anti-TopII for insulin requirement in Chinese type 2 DM patients.

The discovery of a brand new autoantibody in type 1 DM might provide great potential for the development of more powerful predictive or diagnostic tools. However, we cannot achieve this goal without complete understanding of the characteristics of the newly identified autoantibody. We believe the thorough identification and characterization of a new autoantibody could increase the possibility of predicting the disease and might ultimately prevent it, especially in the different pathogenic process in Chinese type 1 DM compared with that of Caucasian patients. Here, we present the relationship between our newly identified autoantibody, anti-TopII, with other autoantibodies in Chinese type 1 DM patients. Hopefully, this study will contribute to the understanding of the putative different autoimmune pathogenesis and provide new monitoring strategies in Chinese diabetic patients.

\section{Materials and methods}

\section{Study subjects and determination of thyroid autoantibodies}

Sera of 201 Chinese patients with type 1 DM (83 males, 113 females) were obtained from the Department of Medicine, Veterans General Hospital, Taipei. The mean age and age at onset were $14.3 \pm 0.6$ years $(3.2-45$ years $)$ and $9.6 \pm 0.5$ years $(0.2-35$ years $)$ respectively, with a mean disease duration of $4.5 \pm 0.2$ years $(0.25-$ 20 years) (Table 1 ). The clinical diagnosis of type $1 \mathrm{DM}$ was confirmed by undetectable or low fasting serum C-peptide concentrations $(<0.3 \mathrm{nmol} / \mathrm{l})$. C-peptide was determined by radioimmunoassay (GPserumM1221, Novo, Vagaswaerd, Denmark). The interassay coefficient of variation $(\mathrm{CV})$ and the intra-assay $\mathrm{CV}$ were $8.0 \%$ and $6.9 \%$ respectively, with a minimum detection level of $0.1 \mathrm{nmol} / \mathrm{l}$. Antithyroglobulin (ATA) and antimicrosomal antibodies (AMiA) were determined by hemagglutination assay (Fujirebio, Tokyo, Japan). The 
Table 1 Clinical characteristics of patients with Chinese type $1 \mathrm{DM}$ in relation to their ATA/AMiA and C-peptide positivity. Results are means \pm S.E.M. Data in parentheses (except for percentages) are the $95 \%$ confidence interval.

\begin{tabular}{|c|c|c|c|}
\hline & \multicolumn{3}{|c|}{ Patient group } \\
\hline & Total & $\begin{array}{c}\text { C-peptide } \\
(>0.3 \mathrm{nmol} / \mathrm{l})\end{array}$ & ATA/AMiA ${ }^{+}$ \\
\hline Number & 201 & 23 & 27 \\
\hline $\operatorname{Sex}(M / F)$ & $83 / 113$ & $11 / 12$ & $6 / 21$ \\
\hline Age (years) & $\begin{array}{l}14.3 \pm 0.6 \\
(13.1-15.5)\end{array}$ & $\begin{array}{l}16.9 \pm 1.8 \\
(13.3-20.5)\end{array}$ & $\begin{array}{l}16.4 \pm 1.5 \\
(13.4-19.4)\end{array}$ \\
\hline Age of onset (years) & $\begin{array}{l}9.6 \pm 0.5 \\
(8.6-10.6)\end{array}$ & $\begin{array}{l}14.2 \pm 1.6^{\dagger^{\prime}} \\
(11.0-17.4)\end{array}$ & $\begin{array}{l}11.1 \pm 1.6 \\
(7.9-14.3)\end{array}$ \\
\hline Duration (years) & $\begin{array}{l}4.5 \pm 0.2 \\
(4.1-4.9)\end{array}$ & $\begin{array}{l}2.8 \pm 0.5^{\dagger} \\
(1.8-3.8)\end{array}$ & $\begin{array}{l}5.2 \pm 0.5 \\
(4.2-6.2)\end{array}$ \\
\hline ATA/AMiA postivity & $27(13.4 \%)$ & $1(4.35 \%)$ & - \\
\hline C-peptide (>0.3 nmol/l) & 23 (11.4\%) & - & $1(3.7 \%)$ \\
\hline titer & $\begin{array}{l}0.13 \pm 0.03 \\
(0.07-0.19)\end{array}$ & $\begin{array}{l}1.06 \pm 0.2^{\dagger} \\
(0.66-1.46)\end{array}$ & $\begin{array}{l}0.04 \pm 0.03 \\
(0-0.1)\end{array}$ \\
\hline Anti-GAD positivity & $92(45.8 \%)$ & $9(39.1 \%)$ & $21(77.8 \%)^{\dagger}$ \\
\hline & $\begin{array}{l}15.6 \pm 2.6 \\
(10.4-20.8)\end{array}$ & $\begin{array}{l}29.0 \pm 11.1 \\
(6.8-51.2)\end{array}$ & $\begin{array}{l}26.3 \pm 7.6 \\
(11.1-41.5)\end{array}$ \\
\hline Anti-Topll positivity & $101(50.2 \%)$ & $10(43.5 \%)$ & 19. $(70.4 \%)^{\dagger}$ \\
\hline
\end{tabular}

${ }^{\dagger} P<0.05$.

test was interpreted as positive if the final serum dilution was 1:100 or higher. Autoantibody against topoisomerase II was determined by enzyme-linked immunosorbant assay as described previously (28). For controls, 51 healthy non-diabetic subjects were recruited.

\section{Glutamic acid decarboxylase antibody (anti-GAD) assay}

GAD antibody radioimmunoassay (RIA) was performed using an anti-GAD RIA kit developed by RSR Ltd, Cardiff, UK. Twenty microliters of test serum samples were first incubated with $50 \mu \mathrm{l}{ }^{125}$ I-labeled human recombinant GAD65 for $2 \mathrm{~h}$ at room temperature. This was followed by the addition of $50 \mu \mathrm{l}$ solid phase protein $\mathrm{A}$, and incubation for $1 \mathrm{~h}$ at room temperature to precipitate the labeled GAD-GAD antibody complexes. After centrifugation at $1500 \times \boldsymbol{g}$ for $30 \mathrm{~min}$ at $4{ }^{\circ} \mathrm{C}$, the supernatants were discarded and the precipitates were counted for ${ }^{125} \mathrm{I}$. The amount of radioactivity in the precipitates is proportional to the concentration of GAD antibody in the test sample. Sera were considered GAD antibody-positive if they contained $>1 \mathrm{u} / \mathrm{ml}$ of antibody, which was more than 4 S.D. above the mean for healthy individuals recommended by RSR Ltd. The interassay CV and the intra-assay CV were 3.1 and $5.1 \%$ respectively.

\section{Statistical analysis}

Results were expressed as mean values ( \pm s.E.) with 95\% confidence interval for each parameter measured. Univariate comparisons were performed using Student's $t$-test for normal distributed data (with unpaired analysis for intergroup comparison) and Chi-square test for diclomatous data. Multivariate analysis, using a multiple logistic regression model with step-down method, was used for interpreting the independent risk factors which increased the incidence of anti-TopII. The data were analyzed using the program SPSS for Windows. All $P$ values were two-tailed, with statistical significance indicated by a value of $P<0.05$.

\section{Results}

Autoantibodies to TopII and GAD were detected by ELISA and radioimmunoassay respectively, using the purified topoisomerase II proteins and anti-GAD RIA kit with purified recombinant human GAD65. When the type of autoantibody present was examined according to the sex, age, age at onset and duration of type 1 DM, a difference in the frequency of anti-GAD and anti-TopII was found.

\section{Frequency of autoantibodies}

Overall, anti-GAD were detected in $45.8 \%(92 / 201)$, anti-TopII in 50.2\% (101/201), and ATA/AMiA in $13.4 \%(27 / 201)$ of our patients (Tables 1 and 2). Although C-peptide was undetectable in the majority of our patients, 23 patients $(11.4 \%)$ remained C-peptidepositive (Table 1). Fifty-two (25.9\%) and 60 (29.8\%) were concurrently positive and negative for anti-TopII and anti-GAD respectively, and 89 patients $(44.3 \%)$ had either anti-GAD or anti-TopII autoantibodies (Table 3). 
Table 2 Clinical characteristics of patients with Chinese type 1 DM in relation to their anti-GAD and anti-Topll positivity. Results are means \pm S.E.M. Data in parentheses (except for percentages) are the $95 \%$ confidence interval.

\begin{tabular}{|c|c|c|c|c|}
\hline & \multicolumn{4}{|c|}{ Patient group $(n=201)$} \\
\hline & Anti-GAD ${ }^{+}$ & Anti-GAD ${ }^{-}$ & Anti-ToplI $^{+}$ & Anti-Top II \\
\hline Number & 92 & 109 & 101 & 100 \\
\hline $\operatorname{Sex}(M / F)$ & $29 / 63$ & $59 / 50$ & $42 / 59$ & $46 / 54$ \\
\hline Age (years) & $\begin{array}{l}15.2 \pm 0.8 \\
(13.6-16.8)\end{array}$ & $\begin{array}{l}13.5 \pm 0.8 \\
(11.9-15.1)\end{array}$ & $\begin{array}{l}15.5 \pm 0.8 \\
(13.9-17.1)\end{array}$ & $\begin{array}{l}13.1 \pm 0.8 \\
(11.5-14.7)\end{array}$ \\
\hline Age of onset (years) & $\begin{array}{l}11.0 \pm 0.7 \\
(9.6-12.4)\end{array}$ & $\begin{array}{l}8.4 \pm 0.7 \\
(7.0-9.8)\end{array}$ & $\begin{array}{l}10.5 \pm 0.7 \\
(9.1-11.9)\end{array}$ & $\begin{array}{l}8.7 \pm 0.7 \\
(7.3-10.1)\end{array}$ \\
\hline Duration (years) & $\begin{array}{l}4.0 \pm 0.3 \\
(3.4-4.6)\end{array}$ & $\begin{array}{l}5.0 \pm 0.4 \\
(4.2-5.8)\end{array}$ & $\begin{array}{l}4.8 \pm 0.4 \\
(4.0-5.6)\end{array}$ & $\begin{array}{l}4.1 \pm 0.3 \\
(3.5-4.7)\end{array}$ \\
\hline Anti-Topll positivity & $52(56.5 \%)$ & $49(45 \%)$ & - & - \\
\hline ATA/AMiA positivity & $21(22.8)^{\dagger}$ & $6(5.5 \%)$ & $19(18.8)^{\dagger}$ & $8(8.0 \%)$ \\
\hline C-peptide $(>0.3 \mathrm{nmol} / \mathrm{l})$ & $9(9.8 \%)$ & $14(12.8 \%)$ & $10(9.9 \%)$ & $13(13.0 \%)$ \\
\hline titer & $\begin{array}{l}0.08 \pm 0.02 \\
(0.04-0.12)\end{array}$ & $\begin{array}{l}0.18 \pm 0.06 \\
(0.06-0.3)\end{array}$ & $\begin{array}{l}0.15 \pm 0.06 \\
(0.03-0.27)\end{array}$ & $\begin{array}{l}0.12 \pm 0.04 \\
(0.04-0.20)\end{array}$ \\
\hline Anti-GAD positivity & - & - & $52(51.5 \%)$ & $40(40 \%)$ \\
\hline titer & $\begin{array}{l}33.76 \pm 4.96 \\
(23.84-43.68)\end{array}$ & $\begin{array}{l}0.25 \pm 0.02 \\
(0.21-0.29)\end{array}$ & $\begin{array}{l}13.6 \pm 3.0 \\
(7.6-19.6)\end{array}$ & $\begin{array}{l}17.6 \pm 4.1 \\
(9.4-25.8)\end{array}$ \\
\hline
\end{tabular}

${ }^{\dagger} P<0.05$.

\section{Association with sex}

A sex difference in the prevalence of anti-GAD, ATA/ $\mathrm{AMiA}$ and the concurrent appearance of anti-GAD and anti-TopII was found. The female to male ratios in all patients and anti-TopII-positive patients were 1.36 $(113 / 83)$ and $1.40(59 / 42)$ respectively, whereas that of the patients carrying anti-GAD, ATA/AMiA and both the anti-GAD and anti-TopII were 2.17 (63/29), 3.50 $(21 / 6)$ and $2.5(37 / 15)$ respectively (Tables $1-3)$. The levels of anti-GAD were also higher among females (mean 34.9 units, range: 1-161.7) than males (mean 22.2 units, range: 1.21-132.24) (data not shown). Anti-GAD positivity in the female and male was $55.7 \%$ and $32.9 \%$ respectively. Our result of gender-related anti-GAD positivity is at variance with other studies where no gender difference of GAD antibody prevalence was seen (32). This discrepancy might be due to the racial difference of type $1 \mathrm{DM}$ pathogenesis.

\section{Associations with age and age at onset}

The mean age of onset in patients carrying C-peptide is older than that in other patients $(14.2 \pm 1.6 \mathrm{vs}$ $9.6 \pm 0.5$ years, $P<0.05$, Table 1$)$. It implied that Chinese patients who suffer type $1 \mathrm{DM}$ at an older age manifest a milder $\beta$-cell destruction. The age of onset in

Table 3 Clinical characteristics of patients with Chinese type 1 DM in relation to their concurrent anti-Topll and anti-GAD positivity. Results are means \pm S.E.M. Data in parentheses (except for percentages) are the $95 \%$ confidence interval.

\begin{tabular}{|c|c|c|c|c|}
\hline & \multicolumn{4}{|c|}{ Patient group $(n=201)$} \\
\hline & $\mathrm{T}^{+} \mathrm{G}^{+\#}$ & $\mathrm{~T}^{+} \mathrm{G}^{-}$ & $\mathrm{T}^{-} \mathrm{G}^{+}$ & $\mathrm{T}^{-} \mathrm{G}^{-}$ \\
\hline Number & 52 & 49 & 40 & 60 \\
\hline $\operatorname{Sex}(M / F)$ & $15 / 37^{\dagger}$ & $27 / 22$ & $14 / 26$ & $32 / 28$ \\
\hline Age (years) & $\begin{array}{l}16.0 \pm 1.0 \\
(14.0-18.0)\end{array}$ & $\begin{array}{l}14.9 \pm 1.3 \\
(12.3-17.5)\end{array}$ & $\begin{array}{l}14.1 \pm 1.2 \\
(11.7-16.5)\end{array}$ & $\begin{array}{l}12.3 \pm 1.0 \\
(10.3-14.3)\end{array}$ \\
\hline Age of onset (years) & $\begin{array}{l}11.5 \pm 0.9^{\dagger} \\
(9.7-13.3)\end{array}$ & $\begin{array}{l}9.4 \pm 1.0 \\
(7.4-11.4)\end{array}$ & $\begin{array}{l}10.3 \pm 1.1 \\
(8.1-12.5)\end{array}$ & $\begin{array}{l}7.5 \pm 0.9 \\
(5.7-9.3)\end{array}$ \\
\hline Duration (years) & $\begin{array}{l}4.3 \pm 1.4 \\
(1.5-7.1)\end{array}$ & $\begin{array}{l}5.4 \pm 0.6 \\
(4.2-6.6)\end{array}$ & $\begin{array}{l}3.5 \pm 0.4 \\
(2.7-4.3)\end{array}$ & $\begin{array}{l}4.5 \pm 0.5 \\
(2.5-6.5)\end{array}$ \\
\hline ATA/AMiA positivity & $16(30.8 \%)^{\ddagger}$ & $3(6.1 \%)$ & $5(12.5 \%)$ & $3(5 \%)$ \\
\hline C-peptide $(>0.3 \mathrm{nmol} / \mathrm{l})$ & $4(7.7 \%)$ & $6(12.2 \%)$ & $5(12.5 \%)$ & $8(13.3 \%)$ \\
\hline titer & $\begin{array}{l}0.06 \pm 0.03 \\
(0-0.12)\end{array}$ & $\begin{array}{l}0.24 \pm 0.11 \\
(0.02-0.46)\end{array}$ & $\begin{array}{l}0.1 \pm 0.04 \\
(0.02-0.18)\end{array}$ & $\begin{array}{l}0.13 \pm 0.05 \\
(0.03-0.23)\end{array}$ \\
\hline Anti-GAD titer & $\begin{array}{l}26.1 \pm 5.4 \\
(15.3-36.8)\end{array}$ & $\begin{array}{l}0.4 \pm 0.03 \\
(0.34 \pm 0.46)\end{array}$ & $\begin{array}{l}43.8 \pm 8.8 \\
(26.2-61.4)\end{array}$ & $\begin{array}{l}0.13 \pm 0.05 \\
(0.03-0.23)\end{array}$ \\
\hline
\end{tabular}

${ }^{\#} \mathrm{~T}$ and G stand for anti-Topll and anti-GAD respectively. ${ }^{\dagger} P<0.05 ;{ }^{\ddagger} P<0.01$. 
Table 4 The prevalence of anti-Topll and anti-GAD in Chinese type 1 DM patients stratified by age, age at onset and duration of disease. Data are expressed as mean and the $95 \%$ confidence interval.

\begin{tabular}{lcc}
\hline \multicolumn{2}{c}{ Prevalence } \\
\cline { 2 - 3 } & Anti-GAD & Anti-Topll \\
\hline Age & & \\
$\mathrm{yr}<11$ & $36.5 \pm 5.6 \%$ & $40.5 \% \pm 5.7 \%$ \\
$11 \leqq \mathrm{yr}<16$ & $57.1 \% \pm 6.7 \%$ & $51.8 \% \pm 6.7 \%$ \\
$16 \leqq \mathrm{yr}<21^{\dagger}$ & $47.6 \% \pm 11.2 \%$ & $71.4 \% \pm 10.2 \%$ \\
$21 \leqq \mathrm{yr}<26^{\dagger}$ & $47.4 \% \pm 11.8 \%$ & $79.0 \% \pm 9.6 \%$ \\
$26 \leqq \mathrm{yr}$ & $57.9 \% \pm 11.6 \%$ & $47.4 \% \pm 11.8 \%$ \\
Onset & & \\
$\mathrm{yr}<6$ & & \\
$6 \leqq \mathrm{yr}<11^{\dagger}$ & $42.2 \% \pm 4.6 \%$ & $44.8 \% \pm 4.6 \%$ \\
$11 \leqq \mathrm{yr}<16$ & $52.6 \% \pm 8.2 \%$ & $71.1 \% \pm 7.5 \%$ \\
$16 \leqq \mathrm{yr}<21$ & $76.9 \% \pm 12.2 \%$ & $61.5 \% \pm 14.1 \%$ \\
$21 \leqq \mathrm{yr}$ & $50.0 \% \pm 15.1 \%$ & $50.0 \% \pm 15.1 \%$ \\
Duration & $60.0 \% \pm 24.5 \%$ & $60.0 \% \pm 24.5 \%$ \\
$\mathrm{yr}<2$ & & \\
$2 \leqq \mathrm{yr}<3$ & $55.6 \% \pm 8.4 \%$ & $41.7 \% \pm 8.3 \%$ \\
$3 \leqq \mathrm{yr}<4$ & $50.0 \% \pm 10.0 \%$ & $50.0 \% \pm 10.0 \%$ \\
$4 \leqq \mathrm{yr}<5$ & $51.5 \% \pm 8.8 \%$ & $54.6 \% \pm 8.8 \%$ \\
$5 \leqq \mathrm{yr}<7$ & $43.5 \% \pm 10.6 \%$ & $52.2 \% \pm 10.7 \%$ \\
$7 \leqq \mathrm{yr}^{\dagger}<11$ & $51.7 \% \pm 9.4 \%$ & $58.6 \% \pm 9.3 \%$ \\
$11 \leqq \mathrm{yr}$ & $41.7 \% \pm 10.3 \%$ & $58.3 \% \pm 10.3 \%$ \\
\hline
\end{tabular}

yr, year.

${ }^{\dagger} P<0.05$.

anti-GAD-positive patients was at the borderline of statistical difference compared with that in anti-GADnegative patients $(11.0 \pm 0.7$ vs $8.4 \pm 0.7$ years, Table 2$)$. This observation indicated that the age of onset of antiGAD-positive patients might have a tendency to be slightly later compared with that of anti-GAD-negative patients. Besides, age of onset in patients carrying both anti-TopII and anti-GAD is statistically older than that of patients without these two antibodies $(11.5 \pm 0.9$ vs $7.5 \pm 0.9$ years, $P<0.05$, Table 3$)$. Taken together, these observations suggest that Chinese patients who develop type $1 \mathrm{DM}$ later tend to derive more than one autoantibody. Table 4 shows the percentage of cases positive for anti-GAD and anti-TopII by age, age at onset and duration. Except for the adolescent age $(47.6 \% \pm$ $11.2 \%$ vs $71.4 \% \pm 10.2 \%$ and $47.4 \% \pm 11.8 \%$ vs $79.0 \% \pm 9.6 \%$ for age between $16-21$ years and $21-$ 26 years respectively, $P<0.05$, Table 4 ), age of onset between $6-11$ years $(52.6 \% \pm 8.2 \%$ vs $71.1 \% \pm 7.5 \%$, $P<0.05$, Table 4) and duration longer than 11 years $(20.0 \% \pm 13.3 \%$ vs $70.0 \% \pm 15.3 \%, P<0.05$, Table 4$)$, there is no significant difference between the prevalence of anti-GAD and anti-TopII in our patients when stratified by age, age at onset and duration. The average level of anti-GAD is also elevated in the adolescent age and age at onset groups but tends to gradually decrease with advancing age (data not shown). Generally, there seems to be no significant difference between the frequency of anti-GAD and anti-TopII among Chinese type $1 \mathrm{DM}$ patients.

\section{Associations with disease duration}

The average disease duration of 23 C-peptide-positive patients was statistically shorter than other patients $(2.8 \pm 0.5$ vs $4.5 \pm 0.2$ years, $P<0.05$, Table 1$)$. The mean duration of anti-GAD-positive patients is also at the borderline of statistically significant difference compared with that in anti-GAD-negative patients $(4.0 \pm 0.3$ vs $5.0 \pm 0.4$ years, Table 2$)$. In a sequential observation, the frequency of anti-GAD is quite constant with longer disease duration but it sharply decreased when the duration of disease is longer than 11 years (from $55.6 \%$ to $20.0 \%$, Table 4 ). Anti-GAD titers tend to decrease regardless of the coexistence of anti-TopII, C-peptide and ATA/AMiA positivity (data not shown). On the other hand, the positivity of anti-TopII is gradually increased rather than decreased with longer duration. The most striking finding is that this increased tendency is obvious and the anti-TopII positivity turned out to be $70.0 \%$ when the duration is longer than 11 years $(41.7 \%$ to $70.0 \%$, Table 4$)$. All the above observations implied that anti-GAD and anti-TopII autoantibodies remain consistent and persistent in Chinese with long-term type 1 DM duration, but antiTopII frequency is more persistent than anti-GAD, especially when the diabetic duration is longer than 11 years. This indicated that anti-TopII, rather than antiGAD, might act as a better indicator for monitoring the pathogenesis of Chinese type 1 DM patients especially in patients with long-standing duration of disease.

\section{Associations of autoantibodies}

Among patients positive for anti-GAD, 22.8\% (21/92) were positive for ATA/AMiA, compared with only $5.5 \%$ $(6 / 109)$ among patients negative for anti-GAD (Table 2 , $P<0.05)$. The ATA/AMiA positivity is also associated with the concurrent appearance of anti-TopII and antiGAD $(30.8 \%, P<0.01$, Table 3$)$. This phenomenon is obvious especially when the patients were anti-GADpositive with titers between 10-50 units (data not shown); in addition, among this subgroup of patients, the C-peptide positivity is much lower $(7.7 \%$, Table 3$)$. It shows that patients who carry more than one antibody might have prominent $\beta$-cell destruction since the $\mathrm{C}$-peptide positivity is lower; however, there is no significant difference in C-peptide levels compared with patients who carry only a single autoantibody.

\section{Comparison of youth- and adult-onset type 1 DM}

The incidence rate of type $1 \mathrm{DM}$ is bimodal: one peak occurs close to puberty, and the other in the fifth decade. To investigate possible differences in these two 
Table 5 Clinical characteristics of patients with youth- and adult-onset Chinese type 1 DM. Results are means \pm S.E.M. Data in parentheses (except for percentages) are the 95\% confidence interval.

\begin{tabular}{|c|c|c|}
\hline & \multicolumn{2}{|c|}{ Patient group } \\
\hline & Children ( $<18$ years) & Adult ( $\geqq 18$ years) \\
\hline Number & 140 & 49 \\
\hline $\operatorname{Sex}(M / F)$ & $57 / 83$ & $24 / 25$ \\
\hline Age (years) ${ }^{\dagger}$ & $\begin{array}{l}6.7 \pm 0.3 \\
(6.1-7.3)\end{array}$ & $\begin{array}{l}25.2 \pm 0.8 \\
(23.5-26.7)\end{array}$ \\
\hline Age of onset (years) ${ }^{\dagger}$ & $\begin{array}{l}3.6 \pm 0.2 \\
(3.2-4.0)\end{array}$ & $\begin{array}{l}18.0 \pm 0.9 \\
(16.2-19.8)\end{array}$ \\
\hline Duration (years) ${ }^{\dagger}$ & $\begin{array}{l}4.5 \pm 0.3 \\
(3.9-5.1)\end{array}$ & $\begin{array}{l}6.9 \pm 0.6 \\
(5.7-8.1)\end{array}$ \\
\hline ATA/AMiA positivity & $18(12.8 \%)$ & $9(18.4 \%)$ \\
\hline C-peptide $(>0.3 \mathrm{nmol} / \mathrm{l})$ & $13(9.28 \%)$ & $8(16.3 \%)$ \\
\hline titer & $\begin{array}{l}0.57 \pm 0.03 \\
(0.51-0.63)\end{array}$ & $\begin{array}{l}1.31 \pm 0.13 \\
(1.05-1.1 .57)\end{array}$ \\
\hline Anti-Topll positivity ${ }^{\dagger}$ & $66(47.1 \%)$ & $32(65.3 \%)$ \\
\hline Anti-GAD positivity & 64 (45.7\%) & $25(51.0 \%)$ \\
\hline titer & $35.2 \pm 4.0$ & $31.4 \pm 6.4$ \\
\hline & $(27.2-43.2)$ & $(18.6-44.2)$ \\
\hline
\end{tabular}

$\dagger P<0.05$

subgroups of Chinese type 1 DM, we divided our patients according to their age of onset and examined the immunological features of 140 children and adolescents (3.3 to 17.9 years old) with 49 adults (18.0 to 45 years old).

The mean duration was longer in adults $(6.9 \pm 0.6$ vs $4.5 \pm 0.3$ years, $P<0.05$, Table 5) and their fasting serum C-peptide concentrations were higher in adultonset type $1 \mathrm{DM}(1.31 \pm 0.13 \mathrm{vs} 0.57 \pm 0.03 \mathrm{nmol} / \mathrm{l}$, $P<0.05$, Table 5). Sixty-four (45.7\%), $66(47.1 \%)$ and $18(12.8 \%)$ out of 140 children were positive for antiGAD, anti-TopII and ATA/AMiA respectively, as compared with $25(51.0 \%), 32(65.3 \%)$ and $9(18.4 \%)$ of 49 adult-onset patients. It indicated that although the duration of adult-onset Chinese type $1 \mathrm{DM}$ is longer, their anti-TopII positivity and $\beta$-cell function is significantly higher and better than that of the juvenileonset Chinese type $1 \mathrm{DM}$ patients.

\section{Univariate and multivariate analysis of anti-TopII}

According to the univariate analysis described above, there is no significant difference in the age, age of onset and duration between anti-TopII-positive and
anti-TopII-negative patients (Table 2) while ATA/AMiA is more prevalent in anti-TopII-positive patients $(18.8 \%$ vs $8 \%$ ). There was also no significant difference in $\mathrm{C}$ peptide and anti-GAD positivity between these two subgroups of patients (Table 2). For further identification of the putative risk factor(s) that increases the incidence of anti-TopII, we recruited the factors of age of onset, duration and ATA/AMiA in the multivariate analysis of anti-TopII positivity. Age is excluded from this multivariate analysis since the age and age of onset are closely related in our patients, such that the patient would definitely be older if the age of onset is later. We can tell from the results of this analysis that the relative risk of onset ( $>18$ years vs $\leq 18$ years) did correlate with anti-TopII positivity (relative risk $=2.15$, Table 6 ). We conclude that the prevalence of anti-TopII is actually associated with the age of onset. It indicated that patients would tend to elicit anti-TopII when they contract the disease when older than 18 years, the adult-onset form of type 1 DM.

\section{Discussion}

In order to testify the putative correlation between antiTopII and other autoantibodies, we examined the

Table 6 Multivariate analysis for the putative risk factor(s) which increases the incidence of anti-Topll.

\begin{tabular}{lcc}
\hline & Relative risk & 95\% confidence interval \\
\hline Onset $(>18$ years old $\leqq 18$ years old $)$ & 2.15 & $1.02-4.53$ \\
Duration $(>3$ years vs $\leqq 3$ years) & 0.98 & $0.53-1.85$ \\
ATA/AMiA $(+$ vs - ) & 2.31 & $0.93-5.71$ \\
\hline
\end{tabular}


autoantibody profiles of 201 Chinese type 1 DM patients; among these patients $45.8 \%$ were positive for anti-GAD, $50.2 \%$ for anti-TopII, $13.4 \%$ for ATA/AMiA and $11.4 \%$ remained C-peptide-positive in this study. Comprehensive demographic data from a large number of Chinese type $1 \mathrm{DM}$ patients, with age and age of onset up to 45 and 35 years make comparison of biological markers in different age groups feasible.

According to the literature, anti-GAD prevalence among Asian groups was relatively low compared with that of Caucasians $(33,34)$. Anti-GAD prevalence rates are reported to be only $5-29 \%$ in Japanese, Koreans, Thais, and Chinese residents of Hong Kong (34-36). However, the frequency of anti-GAD in our patients is higher compared with those results. High rates for antiGAD, similar to the Caucasians, have also been reported $(37,38)$. These controversial observations might be due to the different cut-off values set among laboratories or to other environmental factors that affect the disease pathogenesis, since the dietary habits and living styles are quite diverse in the areas mentioned above even within the same ethnic group. The frequency of antiGAD is highest in our patients who are between 11-16 years old or older than 25 years and with an age of onset of between 11 and 15 years old (Table 4). Chan et al. (36) also found that the prevalence rate for antiGAD positivity is associated with younger age in Chinese patients. However, there is another contradictory study (32) where no age or gender difference of anti-GAD prevalence was seen. An explanation for these discrepant findings is that they might be caused by different mechanisms of pathogenesis among the ethnic groups which resulted in the age-related antiGAD discrepancy. Anti-GAD frequencies are similar in patients with recent-onset type $1 \mathrm{DM}$ compared with those within 10 years of diabetic duration. But the prevalence of anti-GAD is sharply decreased to $20 \%$ in patients with diabetic duration of more than 11 years. It would be interesting to know the mechanism of this overt decrease. However, as yet we have no explanation for the age-related anti-GAD discrepancy or for the mechanism of the sharp decrease in anti-GAD frequency after 11 years of diabetic duration.

When we compared the frequencies of anti-TopII and anti-GAD by stratifying our patients according to age, age at onset and duration, no significant difference was found between the pattern of anti-GAD and anti-TopII positivity except for those of adolescent age, age at onset between $6-10$ years and duration longer than 11 years (Table 1). Although the prevalence and titer of ICA were both reported to decrease with the duration of type 1 DM (39), neither the anti-GAD nor anti-TopII in our patients are transient reactivities. The positivity of antiGAD and especially anti-TopII remained constant and persistent in our patients. The most intriguing finding is that the prevalence of anti-TopII, unlike the tendency for a rapid decrease in ICA, tends to be persistent and even to increase over the long-term duration of disease.
The positivity of anti-TopII is relatively stable regardless of disease duration, and remains as high as $70.0 \%$ in our patients with duration of disease greater than 11 years. Further study is needed to find out if the persistence of anti-TopII in our patients with longterm type 1 DM represents a milder and slower destruction of spleen cells, although we did not find a significant difference in the C-peptide levels between anti-TopII-positive and -negative patients. Although it is too early to answer the above questions at the present stage, anti-TopII might have more potential than ICA and anti-GAD in retrospective studies when looking for islet autoimmunity in type $1 \mathrm{DM}$ patients who were diagnosed years previously because of the persistence of anti-TopII following diagnosis of type 1 DM. In addition, to take advantage of its long-term persistence, antiTopII could be developed and become a new indicator to monitor islet cell destruction or disease progression.

Another interesting observation is that there is a significantly higher female to male ratio $(2.17,63 / 29$, Table 2), higher frequency $(55.8 \%$ vs $33.0 \%)$, and higher median levels (34.9 vs 22.2 units, data not shown) of anti-GAD in females than in males, as well as a higher female to male ratio in ATA/AMiA $(3.5,21 / 6$, Table 1) in our patients. The study by Thai et al. (22) also suggests that anti-GAD in Chinese type 1 DM patients may be gender related. Our observation is in agreement with three other studies (40-42) and supports the view that organ-specific endocrine autoimmunity occurs more frequently in females regardless of racial difference (43). However, anti-GAD was reported to be independent of sex in Caucasian type 1 DM patients (19). The finding that anti-GAD in Chinese type $1 \mathrm{DM}$ is gender related, being more frequent in females than in males, further supports the theory that the autoimmune responses may be operating differently in different ethnic groups and may be gender related in Chinese patients.

Type 1 DM is frequently associated with organspecific autoimmune diseases, including autoimmune thyroid disease, pernicious anemia, and idiopathic Addison's disease (44-47). A significantly higher frequency of ATA/AMiA among anti-GAD-positive than among anti-GAD-negative type $1 \mathrm{DM}$ patients was seen in this investigation $(22.8 \%$ vs $5.5 \%, P<0.05$, Table 2). Also, ATA/AMiA positivity is most prominent in patients with concurrent anti-TopII and anti-GAD positivity $(30.8 \%, P<0.05$, Table 3$)$. This observation is in accordance with the work of Martino et al. (40) and suggests that this may represent a subgroup associated with polyendocrine autoimmunity. This evidence led to speculation that the production of GAD or TopII antibodies in type 1 DM patients with autoimmune thyroid disease might be attributable to a polyclonal activation of the autoimmune system in autoimmune thyroid disease, although this is still controversial and needs further investigation.

There are several inconsistencies in the prevalence of 
anti-GAD between patients with youth- and late-onset type 1 DM. Vanderwalle et al. (48) found that the frequency of anti-GAD in type 1 patients of older (2040 years) age-onset diabetes was higher $(19 / 45,42.2 \%)$ than in those of younger age- onset $(<20$ years $)$ patients $(31 / 82,37.8 \%)$ while Thai et al. (22) concluded that the frequency of anti-GAD was not influenced by whether patients had youth- or adultonset disease. Our results agree with Thai et al. that the youth- or adult-onset type 1 DM does not affect antiGAD frequency. However, we have found that type $1 \mathrm{DM}$ that begins in adulthood is characterized by preservation of residual $\beta$-cell function and higher anti-TopII frequency even though the average duration of type 1 DM in this group is longer than in the youth-onset counterpart. In addition, we found anti-TopII positivity is associated with the age of onset using multivariate analysis of the putative risk factor(s) that increases the incidence of anti-TopII (Table 6). It indicated that Chinese patients would tend to elicit anti-TopII when they contract the disease when they are older than 18 years, the adult-onset form of type 1 DM.

Another subtype of type $1 \mathrm{DM}$ is the slowly progressive form or latent autoimmune diabetes in adults (LADA) (29), a subgroup of type 2 DM patients who eventually require insulin treatment. The characteristics of these patients include age of onset which is significantly higher compared with acute onset type 1 DM, with a peak at around 30-50 years old. It has been suggested that the presence of anti-GAD may identify this subgroup. About 5-9\% of type 2 DM patients are LADA subjects with anti-GAD $(8,9)$. On the other hand, combined screening for IA-2A and anti-GAD has proved to be a powerful approach with which to identify subjects at risk for type $1 \mathrm{DM}$ in large-scale population studies according to several recent reports $(18,19)$. Since the percentage and prediction of LADA in the Chinese population is still an enigma, our finding that anti-TopII positivity is associated with older age of onset is tempting us to investigate whether anti-TopII can differentiate LADA in Chinese type 2 DM. The combination of autoantibodies against TopII, GAD and IA-2 in Chinese patients to assist in the prediction of disease would be interesting, but it awaits further study.

A high proportion of Chinese type $1 \mathrm{DM}$ patients has no evidence of either anti-GAD or ICA (22). It was suggested that differences in etiology may exist between racial groups and it was inferred that other autoantigens of greater relevance have yet to be identified in the Chinese. The identification of new type 1 DM autoantigens is likely to provide novel strategies to predict this disease. In this paper, we have presented and characterized the correlation of immunological features with anti-TopII, and have analyzed the putative associations between various autoantibodies among 201 Chinese type $1 \mathrm{DM}$ patients from a statistical point of view. Above all, we conclude that the involvement of multiple autoantigens or genetic differences within and between ethnic groups can contribute to the heterogenous autoimmune responses in the type $1 \mathrm{DM}$ process. The autoimmune mechanisms in the Chinese type $1 \mathrm{DM}$ are indeed different from the Caucasians, and further investigations should be carried out to explain these differences. Hopefully, we can provide further understanding of the clinical manifestations and immunological responses of Chinese type 1 DM patients through this study.

\section{Acknowledgements}

The authors wish to thank Ms Chan-Hwa Fan for her laborious work in the preparation of serum samples and the measurement of ATA/AMiA.

\section{References}

1 Castano L \& Eisenbarth G. Type 1 diabetes: a chronic autoimmune disease of human, mouse and rat. Annual Review of Immunology 19908 647-679.

2 Nerup J, Mandrup-Poulsen T \& Moivig J. Mechanisms of pancreatic $\beta$-cell destruction in type I diabetes. Diabetes Care 198811 (Suppl) 16-22.

3 Bach JF. Mechanisms of autoimmunity in insulin-dependent diabetes mellitus. Clinical and Experimental Immunology 19882 $1-8$.

4 Pujol-Borrell R, Soldevila G \& Buscema M. Inappropriate expression of HLA class II molecules in endocrine epithelial cells: the phenomenon, the new experimental data and comparison with animal models. Journal of Autoimmunity 19892 (Suppl 2) 163-169.

5 Rossini AA, Mordes JP \& Greiner DL. The pathogenesis of autoimmune diabetes. Current Opinion in Immunology 198919902 598-603.

6 Baekkeskov S, Neilsen JH \& Marner B. Autoantibodies in newly diagnosed diabetic children immunoprecipitate human pancreatic islet cell proteins. Nature 1982298 167-169.

7 Baekkeskov S, Aanstoot HJ, Christgau S, Reetz A, Cascalho M, Folli $\mathrm{F}$ et al. Identification of the $64 \mathrm{~K}$ autoantigen in insulindependent diabetes as the GABA-synthesizing enzyme glutamic acid decarboxylase. Nature 1990347 151-156.

8 Bottazzo GF, Florin-Christensen A \& Doniach D. Islet cell antibodies in diabetes mellitus with autoimmune polyendocrine deficiencies. Lancet 19742 1279-1283.

9 MacCuish AC, Barnes EW, Irvine WJ \& Duncan LJP. Antibodies to pancreatic islet cells in insulin-dependent diabetics with coexistent autoimmune disease. Lancet 19742 1529-1531.

10 Palmer JP, Asplin CM \& Clemons P. Insulin antibodies in insulindependent diabetics before insulin treatment. Science 1983222 1337-1339.

11 Pietropaolo M, Castano L, Babu S, Buelow R, Kuo YL, Martin S et al. Islet cell autoantigen $69 \mathrm{kD}$ (ICA69): molecular cloning and characterization of a novel diabetes-associated autoantigen. Journal of Clinical Investigation 199392 359-371.

12 Castano L, Russo E, Zhou L, Lipes MA \& Eisenbarth GS. Identification and cloning of a granule autoantigen (carboxypeptidase-H) associated with type I diabetes. Journal of Clinical Endocrinology and Metabolism 199173 1197-1201.

13 Jones DB, Junter NR \& Duff GW. Heat-shock protein 65 as a B-cell antigen of insulin-dependent diabetes. Lancet $1990336583-585$.

14 Christie MR, Hollands JA, Brown TJ, Michelsen BK \& Delovitch TL. Detection of pancreatic islet $64000 \mathrm{M}$ sub $\mathrm{r}$ autoantigens in insulin-dependent diabetes distinct from glutamate decarboxylase. Journal of Clinical Investigation 199392 240-248.

15 Lu J, Li Q, Xie H, Chen ZJ, Borovitskaya AE, Maclaren NK et al. Identification of a second transmembrane protein tyrosine 
phosphatase, IA- $2 \beta$, as an autoantigen in insulin-dependent diabetes mellitus: precursor of the $37 \mathrm{kDa}$ tryptic fragment. Proceedings of the National Academy of Sciences of the USA 199693 2307-2311.

16 Notkins AL, Zhand B, Matsumoto Y \& Lan MS. Comparison of IA- 2 and IA- $\beta$ and with six other members of the protein tyrosine phosphatase family: recognition of antigenic determinants by IDDM sera. Journal of Autoimmunity 199710 245-250.

17 Li Q, Borovitskaya AE, DeSilva MG, Wasserfall C, Maclaren NK, Notkins AL et al. Autoantigens in insulin-dependent diabetes mellitus: molecular cloning and characterization of human IA-2 $\beta$. Proceedings of the Association of American Physicians 1997 109 429-439.

18 Pietropaolo M, Peakman M, Pietropaolo SL, Zanone MM, Foley TP Jr, Becker DJ et al. Combined analysis of GAD65 and ICA512(IA-2) autoantibodies in organ and non-organ-specific autoimmune diseases confers high specificity for insulin-dependent diabetes mellitus. Journal of Autoimmunity 199811 1-10.

19 Wiest-Ladenburger U, Hartmann R, Hartmann U, Berling K, Böhm BO \& Richter W. Combined analysis and single-step detection for GAD65 and IA2 autoantibodies in IDDM can replace the histochemical islet cell antibody test. Diabetes 199746 565-571.

20 Clare-Salzler MJ, Tobin AJ \& Kaufman DL. Glutamate decarboxylase: an autoantigen in IDDM. Diabetes Care 199215 132-135.

21 Rowley MJ, Mackay IR, Chen Q-Y, Knowles WJ \& Zimmet P. Antibodies to glutamic acid decarboxylase discriminate major types of diabetes mellitus. Diabetes $199241548-551$.

22 Thai AC, Ng WY, Loke KY, Lee WRW, Lui KE \& Cheah JS. AntiGAD antibodies in Chinese patients with youth and adult-onset IDDM and NIDDM. Diabetologia 199740 1425-1430.

23 Chan SH, Thai AAC, Lin YN, Lui KF \& Wee GB. Influence of gender and age at onset on the HLA association in Chinese with insulin-dependent diabetes mellitus. Human Immunology 199544 175-180.

24 Wang JC. DNA topoisomerases. Annual Review of Biochemistry $198554665-697$.

25 Sternglanz R. DNA topoisomerases. Current Opinion in Cell Biology $19891533-535$.

26 Austin CA \& Fisher LM. DNA topoisomerases: enzymes that change the shape of DNA. Science Progress 199074 147-161.

27 Osheroff N, Zechiedrich EL \& Gale KC. Catalytic function of DNA topoisomerase II. Bioassays 199113 269-273.

28 Chang YH, Hwang J, Shang HF \& Tsai ST. Characterization of human DNA topoisomerase II as an autoantigen recognized by patients with IDDM. Diabetes 199645 408-414.

29 Zimmet PZ, Tuomi T, Mackay IR, Rowley MJ, Knowles W, Cohen $\mathrm{M}$ et al. Latent autoimmune diabetes mellitus in adults (LADA): the role of antibodies to glutamic acid decarboxylase in diagnosis and prediction of insulin dependency. Diabetes Medicine 199411 299-303.

30 Tuomi T, Groop LF, Zimmet PZ, Rowley MJ, Knowles W \& Mackay IR. Antibodies to glutamic acid decarboxylase reveal latent diabetes mellitus in adults with a non-insulin-dependent onset of diabetes. Diabetes 199342 359-362.

31 Niskanen LK, Tuomi T, Karjalainen J, Groop LC \& Uusitupa MJJ. GADab in NIDDM. Ten-year follow-up from the diagnosis. Diabetes Care 199518 1557-1565.

32 Seissler J, de Sonnaville JJ, Morgenthaler NG, Steinbrenner H, Glawe D, Khoo-Morgenthaler UY et al. Immunological heterogeneity in type I diabetes: presence of distinct autoantibody patterns in patients with acute onset and slowly progressive disease. Diabetologia $199841891-897$.

33 Park Y, Lee HK, Koh CS, Min H, Rowley M, Mackay IR et al. The low prevalence of immunogenetic markers in Korean adult-onset IDDM patients. Diabetes Care 199619 241-245.
34 Tuomi T, Zimmet P \& Rowley M. Differing frequency of autoantibodies to glutamic acid decarboxylase among Koreans, Thais, and Australians with diabetes mellitus. Clinical Immunology and Immunopathology 199574 202-206.

35 Zimmet PZ, Rowley MJ \& Mackay IR. The ethnic distribution of antibodies to glutamic acid decarboxylase: presence and levels in insulin-dependent diabetes mellitus in Europid and Asian subjects. Journal of Diabetes and its Complications $199371-7$.

36 Chan JC, Yeung VT, Chow CC, Ko GT, Mackay IR, Rowley MJ et al. Pancreatic $\beta$ cell function and antibodies to glutamic acid decarboxylase (anti-GAD) in Chinese patients with clinical diagnosis of insulin-dependent diabetes mellitus. Diabetes Research and Clinical Practice 199632 27-34.

37 Akasawa S, Kawasaki E, Yano M, Abiru N, Yamaguchi Y \& Nagataki S. Autoantibodies to glutamic acid decarboxylase (GAD), 64000-Mr islet cell protein $(64 \mathrm{~K})$ antibodies and islet cell antibodies (ICA) in insulin-dependent diabetes mellitus with and without autoimmune disease in Japan. Diabetes Research and Clinical Practice 199424 (Suppl) S89-S93.

38 Yano M, Moriuchi R \& Kawasaki E. Autoantibodies against glutamic acid decarboxylase 65 in Japanese patients with insulindependent diabetes mellitus (IDDM). Journal of Autoimmunity $1995883-96$.

39 Kobayashi T, Sugimoto T, Itoh T, Kosaka K, Tanaka T, Suwa S et al. The prevalence of islet cell antibodies in Japanese insulindependent and non-insulin-dependent diabetic patients studied by indirect immunofluorescence and by a new method. Diabetes $198635335-340$.

40 Martino GV, Tappaz ML \& Braghi S. Autoantibodies to glutamic acid decarboxylase (GAD) detected by an immuno-trapping enzyme activity assay: relation to insulin-dependent diabetes mellitus. Journal of Autoimmunity 19914 915-923.

41 Chen QY, Rowley MJ \& Byrne GC. Antibodies to glutamic acid decarboxylase in Australian children with insulin dependent diabetes mellitus and their first degree relatives. Pediatric Research $199334785-790$.

42 Verge CF, Howard NJ, Rowley MJ, Mackay IR, Zimmet PZ, Egan M et al. Anti-glutamate decarboxylase and other antibodies at the onset of childhood IDDM: a population-based study. Diabetologia 199437 1113-1120.

43 Tunbridg WNG, Evered D, Hall R, Appleton D, Brewis M, Clar F et al. The spectrum of thyroid disease in a community: the Wickham survey. Clinical Endocrinology 19777 481-493.

44 Fialkow PJ, Zavala C \& Nielsen R. Thyroid autoimmunity: increased frequency in relatives of insulin-dependent diabetes patients. Annals of Internal Medicine 197583 170-176.

45 Betterle C, Zanette F, Pedini B, Presotto F, Rapp LB, Monociotti CM et al. Clinical and subclinical organ-specific autoimmune manifestations in type I (insulin-dependent) diabetic patients and their first-degree relatives. Diabetologia 199026 431-436.

46 Munichoodappa C \& Kozack GP. Diabetes mellitus and pernicious anemia. Diabetes $199019719-723$.

47 Beaven DW, Nelson DH, Renold AE \& Thorn GW. Diabetes mellitus and Addison's disease: a case report of eight patients and a review of 55 cases in the literature. New England Journal of Medicine 1959 $261443-454$.

48 Vandewalle CL, Falorni A, Svanholm S, Lernmark A, Pipeleers DG \& Gorus FK. High diagnostic sensitivity glutamate decarboxylase autoantibodies in insulin-dependent diabetes mellitus with clinical onset age 20-40 years. The Belgian Diabetes Registry. Journal of Clinical Metabolism 199580 846-851.

Received 19 August 1999

Accepted 26 January 2000 